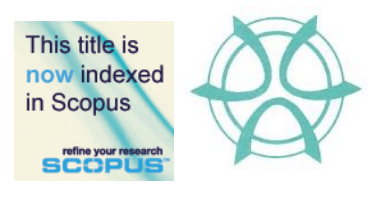

PLANNING MALAYSIA:

Journal of the Malaysian Institute of Planners

VOLUME 15 ISSUE 2 (2017), Page 97 - 108

\title{
RESIDENTS' PERSPECTIVE ON CYCLING AS AN OPTION FOR TRANSPORTATION IN PUTRAJAYA
}

\author{
Siti Fatimah Hashim ${ }^{1}$, Habsah Hashim ${ }^{2}, \&$ Kamarul Bahrain Shuib ${ }^{3}$ \\ ${ }^{1,2,3}$ Faculty of Architecture, Planning and Surveying \\ UNIVERSITI TEKNOLOGI MARA (UiTM)
}

\begin{abstract}
The Federal Government and local authorities, including Putrajaya Corporation, has introduced various initiatives to promote more sustainable transportation options such as encouraging the use of public transportation, walking and cycling in order to reduce the need to travel by car. This paper discusses the findings of the study done among the local residents in Precinct 1, 10,11, 14 and 15 Putrajaya regarding their patterns of cycling as well as their perspectives on the use of bicycles as a mode of transportation. The study employs quantitative methodology. Primary data were gathered by direct interviews at respondent's home or at the local commercial area. The study analyses residents' awareness about the sustainability of cycling, their opinion on the lack of bicycle usage and their willingness to use bicycle as a sustainable mode of transportation. It was found that respondents were aware of the benefits of cycling but hesitant to adopt cycling as mode of transportation for their daily trips. Based on the residents' perspective and the pattern of bicycle usage in their daily life, several suggestions are outlined at the end of the paper with the aim of promoting cycling as a choice of transportation towards greener cities and more sustainable urban neighbourhoods.
\end{abstract}

Keywords: Cycling, sustainable transportation, urban neighbourhoods

Date Received: $26^{\text {th }}$ July 2016

Date of Acceptance: $6^{\text {th }}$ July 2017 
Residents' Perspective on Cycling as an Option for Transportation in Putrajaya

Siti Fatimah Hashim, Habsah Hashim, \& Kamarul Bahrain Shuib

\section{INTRODUCTION}

The first thrust that the National Urbanization Policy was built upon, called for "an efficient and sustainable urban development" (Federal Department of Town and Country Planning, 2006). In line with this target, the Malaysian government had attempted to provide policies to bring about a better quality of life to the people. Among these include the various initiatives to promote more sustainable transportation in order to reduce the need to travel by car. The government has introduced initiatives such as promoting the use of bicycles in major city centres to reduce traffic congestion and air pollution. A study conducted by the Federal Department of Town and Country Planning (FDTCP) and the Ministry of Urban Wellbeing, Housing and Local Government (MUWHLG) (2013) reported that cycling (a sustainable transportation option) can reduce up to six kilograms of carbon in a day compared to the utilization of motor vehicles.

Even though there are indications that the use of bicycles in the city is growing, the majority of the people do not use bicycles as a primary mode of transportation. For some, the presence of bicycle infrastructure and safe streets may be among the factors they consider when choosing a place to live. However, this does not translate into their motivation to opt for cycling nor does it translate into actions towards reducing their carbon footprints.

The development of Putrajaya was based on the concept of garden city with a network of open spaces and recreational areas covering 38.83 percent of the total area. The Perbadanan Putrajaya, the local authority of the area, has also included integrated cycle lane in the planning of Putrajaya (Unit Perancangan Bandar Perbadanan Putrajaya, 2009). The authority has also introduced initiatives to promote more sustainable transportation options such as encouraging the use of public transportation, walking and cycling (Bonsall, 2005). Yosri Abu Mahsin (2000) reports that among these initiatives include the launching of several bicycling campaigns to inculcate a cycling culture while promoting a healthy lifestyle and improving fitness among the civil servants in Putrajaya. Unfortunately, despite these efforts, private car remains as the primary mode of transportation chosen by most residents in Putrajaya.

Therefore, the need to promote cycling as a choice of transportation in line with creating greener cities and more sustainable urban neighbourhoods has become the basis for undertaking this study.

\section{CYCLING AS A MODE OF TRANSPORTATION}

"Vehicles with zero emissions, zero fuel consumption and virtually zero impact on pedestrians, cyclists, and urban population densities might be "green" but then we might as well have rediscovered the bicycle or feet."

(Whitelegg, 1993: 323) 
PLANNING MALAYSIA

Journal of the Malaysia Institute of Planners (2017)

Many authors share the view that cycling helps protect the environment. Whitelegg (1993) expresses concern for the environment and explains that green transportation is often an important consideration in the amelioration of urban transportation problems. Martens (2004) states that bicycle is one mode of transportation that is efficient because of its ability to avoid traffic congestion; it does not consume any fuel and contributes to traffic management such as feeder trips made by car. Wen (2014) reinforces this by stating that the use of bicycles could reduce traffic congestion, lessen environmental pollution and emit zero carbon. Bauman et al. (2008) also agree that cycling has various benefits such as improving health, protecting the environment, becoming a mode of transportation, spurring economic growth and enhancing social ties.

The U.S. Department of Transportation (2015) define cycling as the use of bicycle for sports, transportation and recreation. 'Cyclist', 'bicyclists' or 'bikers' refer to people who are involved in cycling. There are two main purposes of cycling i.e. cycling for leisure and cycling for utility. Cycling for leisure involves pursuing and participating in the trip itself. Leisure cyclists include sports training cyclist, cycle tourists and recreational cyclist. On the other hand, utility cycling involves making a journey for the purpose of doing an activity at the trips' end such as going for shopping, getting education and getting to work. The New Zealand Land Transport Safety Authority (2004) grouped cycling into four types, namely the neighbourhood cycling, sports adults, recreation cycling and touring cycling. Konski Engineers (1977) categorized four types of cyclists such as follows:

i. Category I -The Racer, the Sportsman, the Randonneur, the Connoisseur of cycling

ii. Category II - The Tourist, the Commuter, the Recreationalist.

iii. Category III - The Shopper, the Newcomer; the Neighbourhood Rider.

iv. Category IV - Children Cyclists, including most children from 7 to 8 to 11 or 16 years of age.

\section{PLANNING FOR CYCLE LANES}

According to Konski Engineers (1977), among the factors that affect the magnitude of bicycle usage in a given area include the trip length, trip purpose, climate and topography. A cycle lane plan is the organization of the facilities and the most suitable treatment to the existing lane which will ensure that cyclists are safe and comfortable throughout most part of their journey (Bach \& Diepens, 2000). Dorrestyn (1996) states that the facilities being provided will vary depending on the environment, surrounding development and the types of cyclists who pass through. A good plan produces cycle lanes which provide the highest level of service (LOS) for cyclists, considering safety measures, ensuring convenience and comfort, as well as integrate spaces for cyclists and other users in order to reduce conflict (Cumming, Barber \& Smithers, 1999). 
Residents' Perspective on Cycling as an Option for Transportation in Putrajaya

Siti Fatimah Hashim, Habsah Hashim, \& Kamarul Bahrain Shuib

The Federal Department of Town and Country Planning (FDTCP) and the Ministry of Urban Wellbeing, Housing and Local Government (MUWHLG) (2013) divide cycle lanes into eight types such as follows:

i. Bike path (specific for cyclist, may share with pedestrians and in the urban areas only);

ii. Independent bike path (separated for roads, usually provided along the rivers or in the parks);

iii. Bike path adjacent to pedestrian walkways;

iv. Separated roadside cycle lane;

v. Controlled cycle lane (along the road bordered by separator sill, buffer or strip);

vi. Cycle lanes (along the road separated from motor vehicles by using road signage);

vii. Cycle trails (usually along low volume road and recreation areas, road sign provided); and

viii. Mixed used (could be dangerous to cyclist and cause conflict among road users).

\section{EXISTING CONDITION IN PUTRAJAYA}

Putrajaya applies the neighbourhood concept in planning its residential areas. With this concept, neighbourhoods within each precinct are integrated into the larger residential zones that are well served with basic facilities. Each neighbourhood is defined by roadways, open spaces or housing blocks and parks. In addition, each residential precinct must have at least one neighbourhood park and simultaneously located near a larger park beyond its boundary.

However, urban planning observers commented that the existing living condition in Putrajaya is far from what the plan envisages. Moser (2009) states that although the concept of New Urbanism emphasizes on dense building and walkability, the implementation of these principles in Putrajaya is still low. In terms of walkability for example, Moser notes that "it is a long hot walk to get to anywhere" and there are no trees that provide shade for the pedestrian. Moreover, there is no continuity from the public transportation terminals to the various places that people wanted to go. As such, the current scenario in most places in Putrajaya does not attract people to walk. Residents and visitors in Putrajaya also seem to ignore the policy of reducing automobile-dependence. Most people still use private vehicles to reach their destinations. One of the main shortcomings in Putrajaya planning is the failure to provide shade for pedestrians and cyclists along the streets especially along the broad formal avenues. Users are exposed to direct sunlight. The lack of shade along the major thoroughfare and residential streets discourages green forms of transportation such as walking and cycling. 
PLANNING MALAYSIA

Journal of the Malaysia Institute of Planners (2017)

\section{RESEARCH METHODOLOGY}

The study seeks to evaluate the resident's awareness and cycling pattern in Putrajaya towards promoting a cyclist-friendly environment for sustainable development. The study area covers Precincts 1,10,11, 14 and 15, with a total area of 1,204.54 hectares. The precincts were chosen due to their characters and function as the urban neighbourhoods or residential areas. The total number of houses in the precincts is 2,947. The selection of respondents excluded Precinct 1 as it is a commercial area, government offices area and public parks. The sample size was 116 respondents, which was derived using the "Raosoft Sample Size Calculator" with 92 percent confidence level. The sample was taken proportionately to represent the four types of houses in the study area - terraced houses (40 respondents), semi-detached houses (18 respondents), detached bungalows (18 respondents) and apartments (40 respondents).

Samples were selected using systematic sampling. For each Precinct, the starting point for respondents' selection was randomly determined and upon successful interview, subsequent respondents were systematically selected by skipping 3 houses and selecting the fourth house. For unsuccessful attempts (which include empty house, no cooperation or residents not at home), the next house was approached.

A questionnaire survey was used for the interview. Going house to house to get respondents proved challenging for the research team. During the survey, many residents were not willing to cooperate or were not at home. To overcome the lack of response, respondents were also approached and invited to participate in the survey at the nearby commercial area. Besides the residents' survey, observation survey was also conducted to evaluate the existing condition, infrastructure and facilities for cycling in the study area.

The data obtained were analysed quantitatively using the Statistical Package for Social Science (SPSS) software. Besides cross tabulation, correlation analysis was also undertaken for relevant variables. The research analyses residents' awareness including awareness for reducing the town car usage, awareness to use public transportation and awareness about the benefits of cycling in terms of health, environmental conservation and social life. In addition, the study also analyses the reason for constrained use of bicycles in respondent's neighbourhood and their willingness to use bicycle as a sustainable mode of transportation. Based on the residents' perspective and the pattern of bicycle usage in their daily life, several suggestions are outlined at the end of the paper.

\section{FINDINGS AND DISCUSSION}

Table 1 below summarizes the respondents' background. Additionally, it was also found that from the 116 respondents, more that 75 percent were new residents in Putrajaya, whereby they had stayed in the area for less than 7 years. The average household size was 4.09 and 61 percent of the households own at least a bicycle. 
Residents' Perspective on Cycling as an Option for Transportation in Putrajaya

Siti Fatimah Hashim, Habsah Hashim, \& Kamarul Bahrain Shuib

Table 1 Respondents' Profile

\begin{tabular}{|c|c|c|c|}
\hline Variables & Attributes & Frequency & Percent \\
\hline \multirow{2}{*}{ Gender } & Male & 69 & $59.0 \%$ \\
\hline & Female & 47 & $41.0 \%$ \\
\hline \multirow{3}{*}{ Race } & Malay & 82 & $70.7 \%$ \\
\hline & Chinese & 22 & $19.0 \%$ \\
\hline & Indian & 12 & $10.3 \%$ \\
\hline \multirow{3}{*}{ Marital Status } & Single & 42 & $36.2 \%$ \\
\hline & Married & 71 & $61.2 \%$ \\
\hline & Divorced & 3 & $2.6 \%$ \\
\hline \multirow{5}{*}{ Age } & 18 and below & 5 & $4.3 \%$ \\
\hline & $19-28$ & 52 & $44.9 \%$ \\
\hline & $29-38$ & 42 & $36.2 \%$ \\
\hline & $39-48$ & 15 & $12.9 \%$ \\
\hline & 49 and above & 2 & $1.7 \%$ \\
\hline \multirow{4}{*}{$\begin{array}{l}\text { Level of } \\
\text { Education }\end{array}$} & Primary School & 2 & $1.7 \%$ \\
\hline & SPM & 18 & $15.5 \%$ \\
\hline & Diploma & 81 & $69.8 \%$ \\
\hline & Bachelor degree and higher & 14 & $12.1 \%$ \\
\hline
\end{tabular}

\section{Modes of Travel}

Table 2 shows the various modes of transportation that the respondents use for various trips daily. In terms of bicycle usage, less than 14 percent opted for cycling to go to school/college, work and shops. However, 86.21 percent stated that they use bicycle for recreation. The most popular choice of transportation to go to work was private car while private motorcycle was the preferred mode of transportation to go to the shops.

Table 2 Mode of travel and destination

\begin{tabular}{lccccccccc}
\hline \multirow{2}{*}{ Mode } & \multicolumn{2}{c}{$\begin{array}{l}\text { School/ } \\
\text { College }\end{array}$} & \multicolumn{2}{c}{ Work } & \multicolumn{2}{c}{ Shop } & \multicolumn{2}{c}{ Recreation } & \multirow{2}{*}{ Total } \\
\cline { 2 - 11 } & No & $\%$ & No & $\%$ & No & $\%$ & No & $\%$ & $\%$ \\
\hline $\begin{array}{l}\text { Public } \\
\text { Transport }\end{array}$ & 4 & 3.45 & 98 & 84.48 & 10 & 8.62 & 4 & 3.45 & 100.00 \\
\hline Car & 1 & 0.86 & 102 & 87.93 & 11 & 9.48 & 2 & 1.72 & 100.00 \\
\hline $\begin{array}{l}\text { Motor } \\
\text { cycle }\end{array}$ & 4 & 3.45 & 26 & 22.41 & 78 & 67.24 & 8 & 6.90 & 100.00 \\
\hline Bicycle & 2 & 1.72 & 3 & 2.59 & 11 & 9.48 & 100 & 86.21 & 100.00 \\
\hline Walking & 3 & 2.59 & 3 & 2.59 & 4 & 3.45 & 106 & 91.38 & 100.00 \\
\hline Total & 14 & & 242 & & 114 & & 220 & & \\
\hline
\end{tabular}


PLANNING MALAYSIA

Journal of the Malaysia Institute of Planners (2017)

\section{Awareness on Sustainability of Bicycling}

Table 3 shows the respondents' level of awareness based on seven indicators that reflect the sustainability of bicycling. Respondents were unanimous for the first indicator whereby all of them agree to the statement that cycling contributes zero pollution and zero carbon. Respondents were also aware about the other four indicators of sustainability whereby only one or two respondents who answered "no" to these statements. These four questions/statements were about park-andride system, the fact that bicycle is an environmental-friendly mode of transportation, the benefit of cycling towards health and the contribution of cycling towards community ties.

Table 3: Respondents' awareness on sustainability of cycling

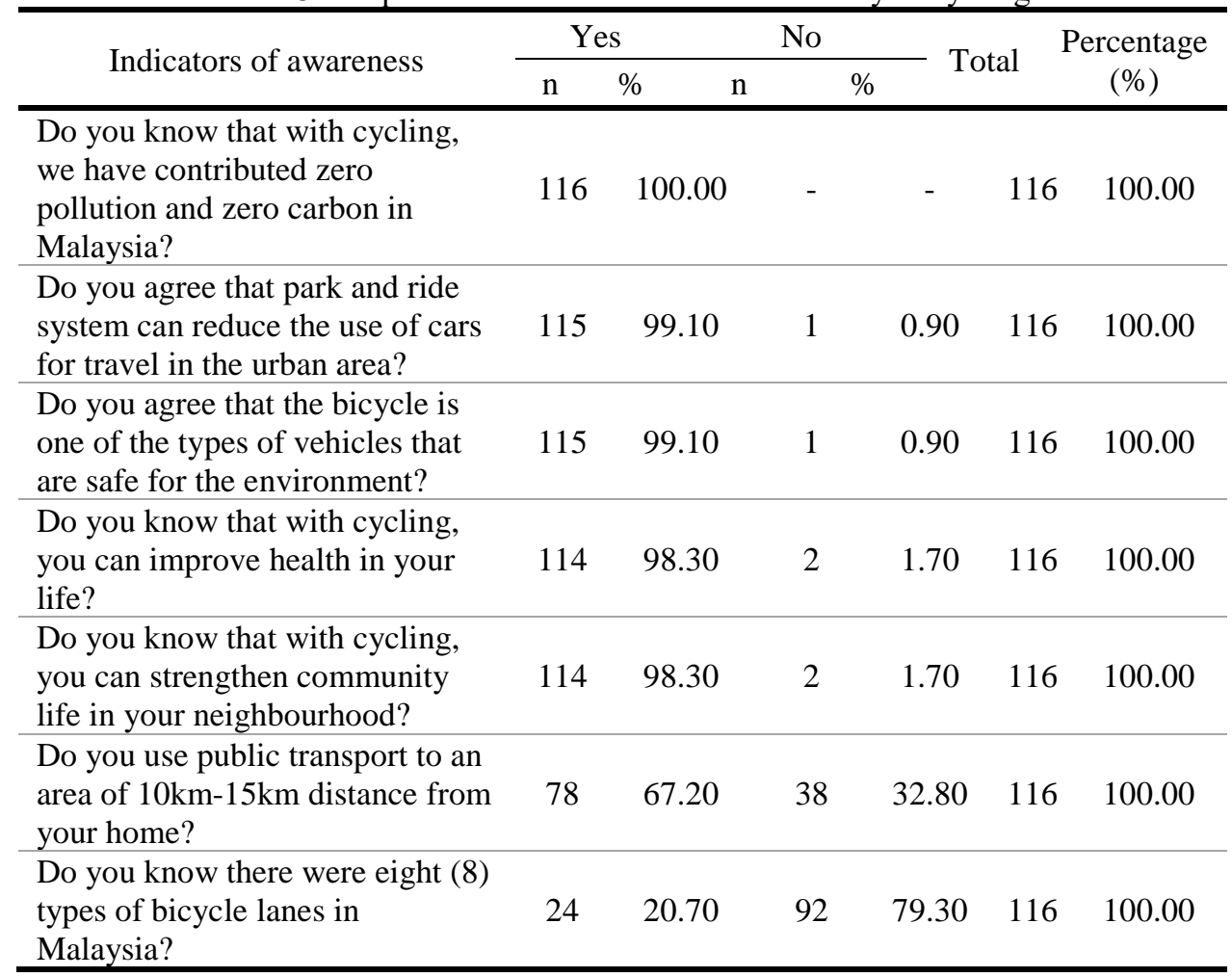

The high level of awareness for the five indicators is a reflection of the residents' concern for preserving the environment and knew that bicycling contributes towards sustainability. It also proves that the various campaign programs on cycling were successful to educate the public. However, for specific knowledge about bicycling, the level of awareness was low. For example, 
Residents' Perspective on Cycling as an Option for Transportation in Putrajaya

Siti Fatimah Hashim, Habsah Hashim, \& Kamarul Bahrain Shuib

majority of the respondents (79.3 percent) answered "no" to the question on whether they knew that there were eight types of bicycle lanes in Malaysia.

Even though for most indicators on sustainability recorded a high level of awareness among the respondents, this is not translated well into practice. When asked whether they use public transportation to a destination of $10 \mathrm{~km}-15 \mathrm{~km}$ distance away, only 67.2 percent answered "yes". This shows that the awareness for using public transportation needs to be increased to encourage more residents switch from using their private car to a more sustainable form of transportation.

\section{Opinion on the Lack of Bicycle Usage}

Table 4 presents the responses from the respondents when asked about the reasons on why they think people were not using bicycle as a means of getting around the neighbourhood for their daily trips. The top most reason agreed by the respondents was the lack of education to residents. Sixteen respondents strongly agree and another 37 respondents agree that this contributed to the lack of bicycle usage. Another 15 respondents strongly agree that the lack of promotion as the main reason. For the other reasons listed in Table 4, more than 70 percent of the respondents expressed a strong disagreement for each item to be the cause for the lack of bicycle usage. Respondents strongly disagree that cycle lane was not well designed, cycle lane was not enough, cycle lane was not well maintained, appropriate infrastructure was lacking and they also disagree that cycling is unsafe and dangerous.

The respondents' opinion shows that neighbourhoods in Putrajaya were equipped with well-designed cycle lanes and reasonably good infrastructure for cycling and most residents were aware of this provision. Residents also felt that the neighbourhood streets and cycle lanes are safe for cyclists.

Table 4 Reasons for the Lack of Bicycle Usage

\begin{tabular}{lrrrrrr}
\hline Reason & 1 & 2 & 3 & 4 & 5 & Total \\
\hline Lack of education to residents & 16 & 37 & 33 & 15 & 15 & 116 \\
\hline $\begin{array}{l}\text { Lack of appropriate } \\
\text { infrastructure }\end{array}$ & 1 & 3 & 3 & 23 & 86 & 116 \\
\hline Lack of promotion & 15 & 2 & 1 & 2 & 96 & 116 \\
\hline Not enough cycle lane & 2 & 1 & 2 & 14 & 97 & 116 \\
\hline Unsafe and dangerous & 1 & 1 & 3 & 14 & 97 & 116 \\
\hline Lack of maintenance & 2 & 2 & 1 & 14 & 97 & 116 \\
\hline Cycle lane not well designed & 2 & 2 & 1 & 13 & 98 & 116 \\
\hline Note: (1) Strongly Agree (2) Agree (3) Slightly Agree (4) Disagree (5) Strongly Disagree & &
\end{tabular}

Observation of the cycle lanes and infrastructure for cycling in the study area revealed that all cycle lanes and infrastructure were in good condition and 
PLANNING MALAYSIA

Journal of the Malaysia Institute of Planners (2017)

the provision was comprehensive. Cycle lanes in the study area were connected to all Precincts and their condition were good. Table 5 shows the provision of cycle lanes and the related facilities in the study area. Figure 1 - Figure 4 portray images of the cycle lanes and facilities.

Table 5 Provision of Cycle Lanes and Cycling Facilities by Precincts

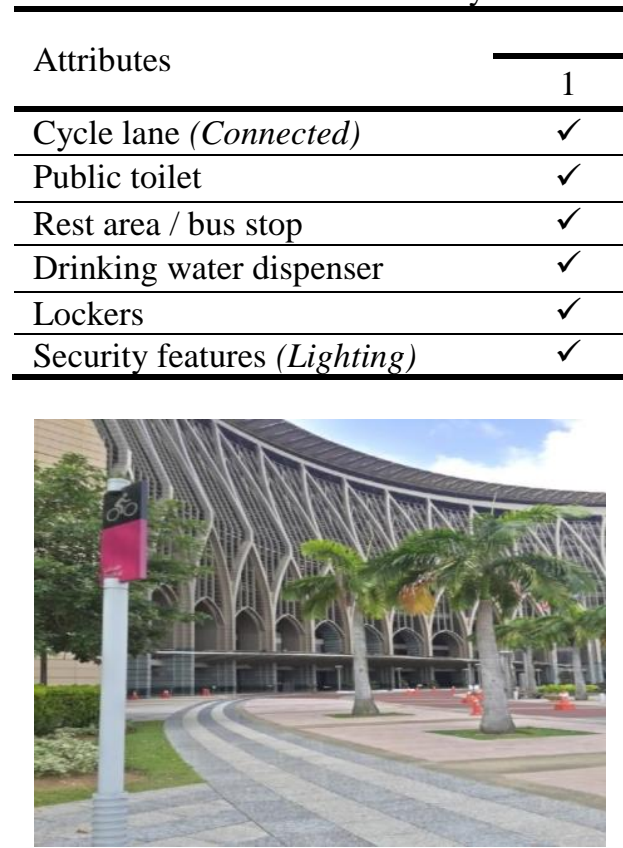

Figure 1 Cycle Lane in Precinct 1

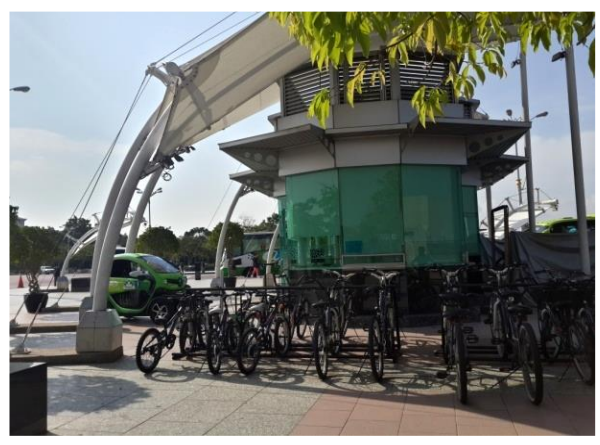

Figure 3 Facilities for Cycling - Bike Parking

\section{Precinct}

$\begin{array}{cccc}10 & 11 & 14 & 15 \\ \checkmark & \checkmark & \checkmark & \checkmark\end{array}$

$\begin{array}{llll} & & & \\ \checkmark & \checkmark & \checkmark & \checkmark\end{array}$

$\begin{array}{llll}\checkmark & \checkmark & \checkmark & \checkmark \\ \checkmark & \checkmark & \checkmark & \checkmark\end{array}$

\begin{tabular}{llll}
$\checkmark$ & $\checkmark$ & $\checkmark$ & $\checkmark$ \\
$\checkmark$ & $\checkmark$ & $\checkmark$ & $\checkmark$ \\
\hline
\end{tabular}

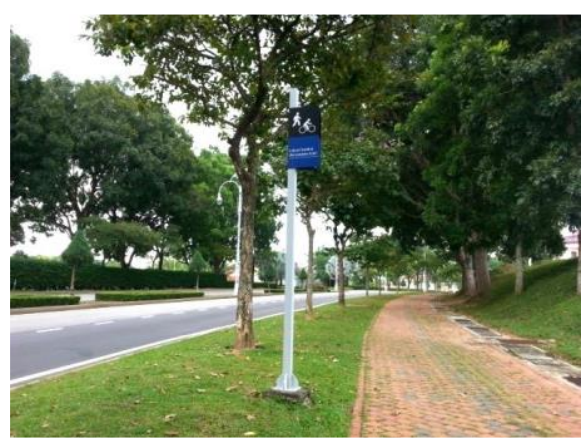

Figure 2 Cycle Lane in Precinct 10

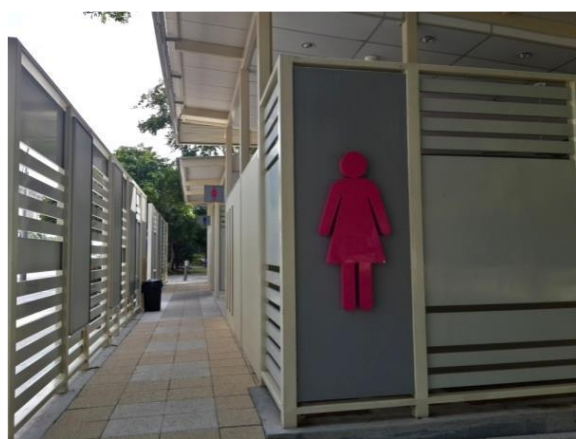

Figure 4 Public Toilet along the Cycle Route 
Residents' Perspective on Cycling as an Option for Transportation in Putrajaya

Siti Fatimah Hashim, Habsah Hashim, \& Kamarul Bahrain Shuib

\section{Willingness to Implement Sustainable Transportation Options}

As listed in Table 6 below, there were five indicators of willingness to implement sustainable transportation options analysed in this study. Feedbacks from the respondents revealed that 80 percent of the respondents were most willing and willing to take necessary actions in order to improve their health and to reduce carbon footprint in their daily lives. In terms of reducing travelling by car, 68.1 percent of the respondents were most willing and willing to reduce their car travel while another 27.5 percent were slightly willing to do so. Only five respondents (less than 5 percent of the respondents) were unwilling to take necessary actions for these three options.

Table 6 Willingness to Implement Sustainable Transportation Options

\begin{tabular}{lcccccccccccc}
\hline & $\begin{array}{c}\text { Most } \\
\text { willing } \\
\text { Attributes }\end{array}$ & \multicolumn{1}{c}{$\begin{array}{c}\text { Willing } \\
(1)\end{array}$} & $\begin{array}{c}\text { Slightly } \\
\text { willing } \\
(3)\end{array}$ & $\begin{array}{c}\text { Unwilling } \\
(4)\end{array}$ & $\begin{array}{c}\text { Very } \\
\text { unwilling } \\
(5)\end{array}$ & Total \\
\cline { 2 - 12 } & No & $\%$ & No & $\%$ & No & $\%$ & No & $\%$ & No & $\%$ & No & $\%$ \\
\hline $\begin{array}{l}\text { Willingness to } \\
\text { improve health }\end{array}$ & 63 & 54.31 & 30 & 25.86 & 18 & 15.51 & 3 & 2.58 & 2 & 1.72 & 116 & 100 \\
\hline $\begin{array}{l}\text { Willingness to } \\
\text { reduce carbon }\end{array}$ & 59 & 50.86 & 34 & 29.31 & 18 & 15.51 & 3 & 2.58 & 2 & 1.72 & 116 & 100 \\
$\begin{array}{l}\text { Willingness to } \\
\text { reduce travel } \\
\text { by car }\end{array}$ & 63 & 54.31 & 16 & 13.79 & 32 & 27.58 & 3 & 2.58 & 2 & 1.72 & 116 & 100 \\
\hline $\begin{array}{l}\text { Willingness to } \\
\text { cycle }\end{array}$ & 35 & 30.17 & 19 & 16.37 & 57 & 49.31 & 3 & 2.58 & 2 & 1.72 & 116 & 100 \\
\hline $\begin{array}{l}\text { Willingness to } \\
\text { walk }\end{array}$ & 33 & 28.44 & 19 & 16.37 & 59 & 50.86 & 3 & 2.58 & 2 & 1.72 & 116 & 100 \\
\hline
\end{tabular}

Based on these three indicators, it can be concluded that in general, the residents in the study area are receptive to change and would want to adopt more sustainable living options. However, when asked whether they are willing to cycle and to walk for their daily trips, less than 50 percent of the respondents were willing to opt for these modes of transportation.

Therefore, from this analysis, it can be concluded that most respondents are willing and ready to reduce carbon, to improve health and to reduce car usage but are less willing to walk and cycle in their daily life. The midday heat and the nature of tropical warm weather coupled with the lack of shaded paths contributed in-part to this low level of willingness.

\section{RECOMMENDATIONS AND CONCLUSION}

The sustainability concept is evident in Putrajaya through the designation of almost 40 percent of its total area specifically for green and open spaces in the Putrajaya Master Plan. Cycling has become popular as more people became 
PLANNING MALAYSIA

aware of the concept of sustainability and wanted to be part of the movement for a greener future city especially in neighbourhoods experiencing constant traffic congestions. However, this study shows that majority of the respondents did not use bicycle as a primary mode of transportation in their daily trips to work, shops and colleges even though the provision of cycle lanes, and the related infrastructure and facilities, were excellent. The residents' survey found that the awareness among residents towards cycling to a destination of $5 \mathrm{~km}$ to $10 \mathrm{~km}$ from their home was not satisfactory. Only four respondents reported using bicycle on a daily basis and 47 percent of the respondents use the bicycle once a week, mostly for recreational purposes.

Based on the analysis and findings, several recommendations to increase the residents' awareness for cycling in the urban neighbourhoods are outlined. These recommendations are categorized into three stages i.e. short term, medium term and long term measures that can be applied in the neighbourhoods of Putrajaya.

In the short term, efforts should be targeted at improving safety and roadway behaviour among cyclists through educational programs, campaigns and promotion in the mass media. In the medium term, measures should focus on programs to promote cycling and increase awareness of cycling among the general public. For instance, program such as 'smart trips' can be implemented in which events such as riding a bicycle in the neighbourhood can be organised so that the population become more familiar and comfortable getting around using alternative mode of transportation. Other programs such as 'Take your cycle to the shop today' program, promoting cycling to work and promoting cycling to school can also be implemented. In the long term, efforts should be aimed at promoting cyclist-friendly environment for sustainable development in neighbourhood areas. An 'all ages and abilities bicycle network plan' can be prepared to plan and to provide an interconnecting system of bicycle lanes and facilities, which are comfortable and attractive for a broad array of users, such as children, youths, families and seniors in the study area.

\section{CONCLUSION}

Findings from this study found that the infrastructure and facilities along the cycle lane and the cycle lane signage were already in very good condition. The cycle lanes were also well connected throughout the several Precincts in the study area. Thus, with the implementation of the recommendations proposed in this paper, the cycle lane could be categorized into family trail, fitness trail and educational trail, and all the trails are connected throughout the neighbourhoods. These proposals could promote a cyclist-friendly environment, attract more residents to leave their cars at home and take the bicycle to the shops, schools or work.

This study is important to improve the quality of the environment as well as public health and fitness. The provision of cycle lane in the urban 
Residents' Perspective on Cycling as an Option for Transportation in Putrajaya

Siti Fatimah Hashim, Habsah Hashim, \& Kamarul Bahrain Shuib

neighbourhood can also enhance the value of land and property. By encouraging cycling within the neighbourhoods, the aim for sustainable development in the urban neighbourhoods could be materialized in Putrajaya.

\section{REFERENCES}

Bauman, A., Rissel, C., Garrard, J., Ker, I., Speidel, R., \& Fishman, E. (2008). Cycling: Getting Australia moving - Barriers, facilitators and interventions to get More Australians physically active through cycling. Melbourne: Cycling Promotion Fund.

Bach, B., \& Diepens, J. (2000.) International handbook for user-group based bikeway design. Unknown Publisher.

Bonsall, P. (2005). Stimulating modal shift. In K. J. Button \& D. A. Hensher (Eds), Handbook of transport strategy, policy and institutions. London: Elsevier.

Cumming, A., Barber, H., \& Smithers, R. (1999). Planning and implementing on-road bicycle networks. In Proceedings of Velozity Australian Cycling Conference 1999, Adelaide, Australia.

Dorrestyn, K. (1996). Metropolitan Adelaide bicycle network. In Proceedings of Velo Australis International Bicycle Conference (pp. 585-594), Fremantle, Australia.

Federal Department of Town and Country Planning [FDTCP] (2006). National urbanization policy. Kuala Lumpur: Ministry of Urban Wellbeing, Housing and Local Government.

Federal Department of Town and Country Planning [FDTCP] \& Ministry of Housing and Local Government [MUWHLG] (2013). Panduan pelaksanaan inisiatif pembangunan kejiranan hijau. penyediaan laluan basikal, Malaysia.

Konski Engineers (1977). Binghamton Metropolitan bikeway system: a plan and program, Binghamton Metropolitan Transportation Study. Binghamton, New York.

Land Transport Safety Authority New Zealand (2004). Cycle network and route planning guide.

Martens, K. (2004). The bicycle as feedering mode: experiences from three European countries. Transportation Research Part D: Transport and Environment, 9(4), 281-294.

Moser, S. (2009). Putrajaya: Malaysia's new federal administrative capital. Cities, 27(4), 285-297.

Unit Perancangan Bandar Perbadanan Putrajaya (2009). Laporan pemeriksaan draf rancangan struktur Putrajaya 2015. Perbadanan Putrajaya, Malaysia.

U.S. Department of Transportation (2015). Active transportation. Retrieved from https://www.transportation.gov/mission/health/active-transportation.

Wen, L. M. (2014). Reliability and construct validity of the Malay version of the cyclist motivation instrument (CMI). Journal of Science and Cycling, 3(3), 3-8.

Whitelegg, J. (1993). Transportation for a sustainable future: the case for Europe. London: Belhaven Press.

Yosri Abu Mahsin. (2000). Berbasikal di Putrajaya tingkatkan kecergasan pejawat awam. Kementerian Belia dan Sukan. 